\title{
RISCO DE INTOXICAÇÃO PROFISSIONAL POR TRICLOROETILENO EM PROCESSOS DE DESENGRAXAMENTO NO MUNICIPIO DE SÃO PAULO, BRASIL
}

Herbert M. A. Stettiner $\dagger$ Jorge da Rocha Gomes * Sérgio Colacioppo

StetTINeR, H. M. A. et al. Risco de intoxicação profissional por tricloroetileno em processos de desengraxamento no municipio de Sáo Paulo, Brasil. Rev. Saúde públ., S. Paulo, 11:395-404, 1977.

ReSumo: A toxicidade de vapores de tricloroetileno (TRI) em locais de trabalho é posta em evidência. Determinou-se a concentração de vapores de TRI no ar em fábricas e oficinas onde o liquido serve para desengraxar peças metálicas. Os metabólitos do TRI, o ácido tricloroacético e o tricloroetanol foram determinados em urina de pessoas expostas. Os resultados destas determinaçóes permitem ver a periculosidade potencial que o uso do TRI apresenta.

UNITERMOS: Tricloroetileno, toxicologia. Medicina do trabalho. Saúde ocupacional.

\section{I N T R D U C $\tilde{A} O$}

O tricloroetileno (TRI) é usado en larga escala nos processos industriais pela sua propriedade de dissolver graxa e gordura. Noventa por cento da produção de TRI é consumida em operações de desengraxamento (limpeza de peças, decapagem de materiais para processos de eletro deposição, e outras). A lavagem a seco de roupas (dry-cleaning) e a extração seletiva de certos alimentos e drogas (como a remoção da cafeina do café) utiliza cinco por cento da produção. O restante é empregado numa miscelânia de operações que abrangem aplicações em pesticidas, resinas, colas, breu, cera, tintas e vernizes.
Como o emprego do TRI envolve riscos à saúde pela toxicidade de seus vapores, os trabalhadores que manuseiam este solvente constituem uma população que necessita observação médico-preventiva cuidadosa. Nos EUA, o National Institute for Occupational Safety and Health (NIOSH) ${ }^{6}$ estimou que 200.000 trabalhadores estão expostos aos riscos do TRI. No Brasil não se tem dados, mas apenas como exemplo, numa das indústrias pesquisadas neste trabalho são consumidos cerca de 20 toneladas mensais de TRI.

Pela quantidade de expostos, pelo que representa esta população em termos econô-

$\dagger$ In memoriam.

* Do Departamento de Saúde Ambiental da Faculdade de Saúde Pública da USP - Ar. Dr. Arnaldo, 715 - São Paulo, SP - Brasil. 
STETTINER, H. M. A. et al. Risco de in toxicação profissional por tricloroetileno em processos de desengraxamento no municipio de S. Paulo, Brasil. Rer. Saúde públ., S. Paulo, $11: 395-404,1977$.

micos (operários produtivos altamente especializados de difícil substituição), pelos métodos preventivos eficientes disponiveis, a utilização deste solvente se constitui num problema de saúde pública, embora mais especificamente de saúcle ocupacional. Neste sentido é que foi elaborado o presente trabalho de avaliação de condiçóes de trabalho de expostos ao TRI e de sua ação sobre o trabalhador.

\section{ASPECTOS MEDICOS}

\subsection{Fisiopatogenia}

A principal via de absorção do TRI é a respiratória e, secundariamente, a via cutânea. Uma vez absorvido, o TRI é fixado pelos eritrócitos e pelo plasma, sendo distribuído pelo organismo com afinidade para o tecido lipóide. A eliminação se faz através do rim, convertido metabolicamente em ácido tricloroacético e tricloroetanol, e tanbém, em pequena escala, pelos pulmões. Experiências em animais demonstraram que o TRI não tem ocasionado lesões severas no rim e no figado, como as encontradas em intoxicações por outros hidrocarbonetos halogenados. Hunter ${ }^{3}, 1971$, relata degeneraçăo gordurosa do fígado e degeneração granular do rim (inalação experimental). Descreve, também, caso fatal de necrose aguda do fígado 12 dias após anestesia prolongada com TRI.

Não há dúvida que o principal risco potencial do TRI é o efeito anestésico. Têm sido relatadas intoxicações ocupacionais cuja sintomatologia consistiu em inconsciência e coma. A grande maioria se recupera bem, já tendo, entretano, ocorrido casos de óbito por fibrilação ventricular, especialmente nas exposições prolongadas em concentrações elevadas ${ }^{6}$.

Certos produtos de decomposição do TRI, ou ainda impurezas oriundas da fabricação, são de elevada toxicidade, como dicloroetano, fosgenio e o tetracloroetano. As vezes os efeitos podem ser atribuídos pri- mordialmente a estas substâncias e não ao próprio TRI10.

\subsection{Manifestaçōes clinicas}

Nas formas super agudas a intoxicação se traduz por inconsciência e coma, chegando à morte por edema agudo do pulmão.

As formas agudas se caracterizam por tonturas e perturbação de equilibrio (embriaguez) com cefaléia, náuseas, fadiga, insônia.

A forma crônica se traduz por transtornos nervosus com sintomas semelhantes às formas agudas leves, mas em caráter mais duradouro. São referidas, nesta fase, certas perturbaçōes digestivas com gastralgias e estado nauseoso, podendo ainda aparecer a anemia.

Além dos efeitos anestésicos gerais mui. to semelhantes ao etilismo crônico, é im portante ainda referir alguns outros atrlbuíveis principalmente à afinidade do TRI pelo tecido nervoso. Assim sendo, já furam descritas lesōes nervosas, atribuíveis ao TRI, dos seguintes pares craneanos: trigêmio (paralisia), olfativo (anosmia), auditivo (surdez), ótico (diplopia, borramento da visão, neurite ótica e mesmo cegueira), glossofaríngeo (perda de sentido do gosto). O sentido do tato também pode estar afetado, podendo ainda ocorrer alterações eletro-encefalográficas (disritmia cortical e irritação) e alteraçōes psíquicas (psicose paranóide temporária). Outro risco a considerar é o da toxicomania; especialmente os empregados que retornam à fábrica durante os fins de semana e nas férias sem uma razão aparente, ou que costumam levar frascos com TRI para suas residências, devem ser investigados quanto a uma possivel dependência ao TRI. Como efeito do TRI ainda são citados casos de icterícia e, embora casos de necrose aguda do fígado também tenham sido descritos, sempre resta dúvida quanto ao estabelecimento formal do nexo causal exposição ao TRI puro e doença; cumpre também referir a possibi- 
STETTINER. H. M. A. et al. Risco de in toxicação profissional por tricloroetileno em processos de desengraxamento no município de S. Paulo, Brasil. Rev, Saúde públ., S. Paulo, $11: 395-404,1977$.

lidade de dermatoses ortoalérgicas (queimaduras e flictenas) e alérgicas (eczemas que em nada se diferenciam dos eczemas devidos a outras substâncias). São ocasionadas pela ação do TRI sobre o tecido gorduroso da pele ${ }^{8}$. Stewart 1"3 realizou interessante experiência sobre erupção eritematosa no rosto e pescoço de pessoas expostas aos vapores do TRI, minutos após tomarem bebida alcoólica.

Recentemente Lloyd e col. ${ }^{5}$ publicaram um ensaio sobre o risco potencial carcinogenético hepático do TRI.

Entre as manifestações clínicas constam ainda efeitos sobre 0 aparelho cardiovascular (fibrilação ventricular, taqui ou bradicardia, dependendo da intensidade da expusição, e alterações eletrocardiográficas).

\subsection{Tratamento e prognóstico}

O tratamento é sintomático. Resume-se no afastamento do empregado da exposi(̧ão) lavagem abundante com água no caso da contaminação da pele ou dos olhos.

\subsection{Prevenção}

Inicia-se no exame pré-funcional, eliminando candidatos com lesões hepáticas, pulmonares, renais ou neurológicas e os que se intoxicaram previamente com o TRI. No exame periódico deve haver cuidadosa avaliação clínica com ênfase nos aspectos neuro-dermatológicos e pulmonares. Recomenda-se também a determinação de compostos triclorados na urina das pessoas expostas, ben como exames laboratoriais das funções hepato-renais.

Outro aspecto importante é instruir o empregado sobre os riscos do TRI e as medidas de seu controle: uso de equipamento de proteção individual, medidas de higiene, abstenção do álcool, primeiros socorros em casos de intoxiaação aguda, e outras. O rítmo da avaliação periódica dependerá das concentrações ambientais, podendo ser semestral ou trimestral, mas de qualquer forma é importante lembrar que há casos de hipersuscetibilidade individual que necessitarão controle mais amiudado, e, eventualmente, afastamento definitivo da exposição ${ }^{12}$. As medidas preventivas mais importantes são as de caráter coletivo e achamse descritas pormenorizadamente por Goelzer ${ }^{2}$ envolvendo entre outros:

- substituição por produto menos tóxico como, por exemplo, 1, 1, 1 tricloretano.

- ventilação adequada

- locais de trabalho apropriados

- manutenção periódica preventiva dos equipamentos

- limpeza cuidadosa dos locais de trabatho.

\section{ASPECTOS LEGAIS}

As atividades ou funções exercidas em locais onde haja exposição ao risco do TRI estão enquadrados como insalubres grau 2 (insalubridade média) de acordo com o quadio V - "Hidrocarbonetos e outros compostos de carbono", da portaria 491 de 16 de setembro de 1965 , do então Ministério do Trabalho e Previdência Social. Os empregados deverão perceber, mensalmente, um adicional de insalubridade correspondente a $20 \%$ do salário mínimo.

$O$ anexo I da Regulamentação de Acidentes do Trabalho (Dec. $\mathrm{n}^{\circ} 79.039$, de 24 de dezembro de 1976) que estabelece a relação de doenças profissionais ou do trabalho não inclui especificamente a intoxicação causada pelo TRI. Poderia, no entanto, ser enquadrada no seu item 9: "causadas pelos hidrocarbonetos da série graxa", embora não seja um enquadramento perfeito.

O TRI está incluido no Decreto 63.230 de 10 de setembro de 1968, que dispõe sobre aposentadoria especial. Os expostos poderăo aposentar-se aos 25 anos de serviço: Quadro I, item 1.2.9. - Hidrocarbonetos e outros compostos de carbono.

A Portaria n: 5, de 21 de janeiro de 1944, publica quadro de serviços insalubres que 
STETTINER, H. M. A. et al, Risco de in toxicação profissional por tricloroetileno em processos de desengraxamento no município de $\mathrm{S}$. Paulo. Brasil. Rcr. Saúde públ., S. Paulo. $11: 395-404.1977$.

são vedados ao menour. O TRI pode ser encuadrado no item 14: Fabricação e manipulação de gases tóxicos.

O Decreto n? 21.417 , de 17 de maio de 1932, também se refere ao quadro de serviços vedados, neste caso à mulher; O TRI está incluido no item: Qualquer trabalho com dissolventes químicos voláteis e inflamáveis".

Em vista dos eteitos tóxicos descritos acima, a "American Conference of Governmental Industrial Hygienists" (ACGIH) estabeleceu em 1961 como limite de tolerância (LT) para " TRI u valor de 100 ppm supondo a exposiçào em jornadas de 8 horas em 5 dias de trabalho por semana. Este valor do LT foi conservado até o ano em curso, e embora nāo tenha força legal no Brasil, adotamo-lo como critério para avaliar a contaminação nos lugares de trabalho onde determinamos os vapores de TRI no ar. Se considerarmos, porém, outros paises, os limites variam desde 200 ppm (República Árabe Unida) até 2 ppm (URSS).

\section{TECNICA DE DESENGRAXAMENTO E EXPOSIÇÃO DO PESSOAL}

Os métodos de desengraxamento adotados nas diversas indústrias e oficinas podem ser caracterizados em dois tipos de procedimentos: com aquecimento ou sem aquecimento do TRI, ou, ent linguagem usual, "a quente" ou "a frio"

\subsection{Aplicafāo "a quente"}

O solvente é aquecido num tanque de fundo retangular. As peças são dependuradas nele, expostas aos vapores do TRI yue se condensa na sua superficie. A graxa aderente se dissolve e a soluçào volta gotejando para o fundo do tanque. Em certa altura do tanque uma serpentina de refrigeração acompanha suas paredes internamente. Serve para facilitar a condensação do TRI sobre as peças e deveria impedir a saida de vapores do tanque; porém, devido à grande volatilidade do TRI, certa quantidade de vapores sempre escapa para fora e deve ser afastada por ventilaçāo local exaustora. Uma tampa completa o aparetho, mas en geral somente é colocada quando o mesmo está fora de uso.

Freqüentemente um operário completa 0 desengraxamento dirigindo um jato de TRI liquido sobre as peças dependuradas no tanque. Esta operação, a colocação das peças no aparelho e sua retirada representam as principais condiçōes de exposição dos operários, mesmo quando a movimentação das peças é efetuada por dispositivos mecànicos.

\subsection{Aplicaşào "a frio"}

Na maioria dos casos o desengraxamentu a frio consiste na simples imersão de algumas peças do TRI liquido contido num vaso aberto. Algumas empresas têm por costume empregar o TRI no lugar de querozene ou gasolina para desengraxar pequenas peças. Este trabalho se executa em ocasiōes tão raras e fora da rotina que não foi incluido na presente pesquisa.

$O$ desengraxamento de tubos e fitas de metal, que também é feito sem aquecimento do TRI, apresenta um aspecto diferente. Para limpar tubos, o dissolvente é bonbeado pelo seu interior, depois sāo secos passando-se uma corrente de ar. As fitas por sua vez são passadas entre panos molhados de TRI e prensados. A embebição dos panos é mantida despejando-se o TRI sobre eles por meio dum vasilhame qualquer. Deste procedimento poderá resultar uma acentuada elevação da concentração ambiental do TRl com o consequente risco ocupacional.

\section{MATERIAL E MÉTODOS}

\subsection{Locais de trabalho e pontos de amostragem}

Por internedio de fabricantes de tricloroetileno, foi estabelecido contato com 10 empresas que utilizam este solvente. Des- 
STETTINER, H. M. A. et al. Risco de in toxicação profissional por tricloroetileno em processos de desengraxamento no município de $\mathbf{S}$. Paulo. Brasil. Rev, Saúde públ., S. Paulo, $11: 395-404,1977$.

T A B E L A 1

Concentraçoses de vapores de TRI em instalações de desengraxamento a quente, segundo o tipo de operação e o ponto de amostragem.

\begin{tabular}{|c|c|c|c|c|c|}
\hline \multirow{2}{*}{ Fábrica } & \multirow{2}{*}{ Operuçãa" } & \multirow{2}{*}{ Ponto } & \multicolumn{3}{|c|}{$\begin{array}{c}\text { Concentração de TRI } \\
\text { no ar em ppm }\end{array}$} \\
\hline & & & minima & máxima & média \\
\hline (1) & Galvanização & $\begin{array}{l}1 \\
3\end{array}$ & $\begin{array}{l}25.7 \\
23.6\end{array}$ & $\begin{array}{l}88.1 \\
32.6\end{array}$ & $\begin{array}{l}54.5 \\
28.0\end{array}$ \\
\hline 02 & Peças plásticas e galvanizadas & $\begin{array}{l}1 \\
3\end{array}$ & $\begin{array}{l}67,4 \\
89,3\end{array}$ & $\begin{array}{l}105.3 \\
113.6\end{array}$ & $\begin{array}{r}86.5 \\
101.5\end{array}$ \\
\hline $0 ;$ & Galvanização & $\begin{array}{l}1 \\
2\end{array}$ & $\begin{array}{r}211.0 \\
22,3\end{array}$ & $\begin{array}{r}409.6 \\
37.0\end{array}$ & $\begin{array}{r}310.5 \\
29.5\end{array}$ \\
\hline 04 & Mecânica e tralvanização & 1 & 47.8 & 54.4 & 51,5 \\
\hline 0.5 & Mecânica e galvanização & $\begin{array}{l}1 \\
2\end{array}$ & $\begin{array}{r}33,9 \\
231,2\end{array}$ & $\begin{array}{r}93.2 \\
279.1\end{array}$ & $\begin{array}{r}62.5 \\
255.0\end{array}$ \\
\hline 118 & Mecânicua & $\begin{array}{l}1 \\
2\end{array}$ & $\begin{array}{l}26,1 \\
24.3\end{array}$ & $\begin{array}{l}188.9 \\
161.7\end{array}$ & $\begin{array}{r}110.5 \\
94.0\end{array}$ \\
\hline 09 & Galvanização tanque 1 & $\begin{array}{l}1 \\
2\end{array}$ & $\begin{array}{l}4,4 \\
3,1\end{array}$ & $\begin{array}{r}18.8 \\
9.0\end{array}$ & $\begin{array}{l}9.5 \\
6.0\end{array}$ \\
\hline 09 & Galvanização tanque 2 & $\begin{array}{l}1 \\
2\end{array}$ & $\begin{array}{l}11,7 \\
42,8\end{array}$ & $\begin{array}{r}15.8 \\
\mathbf{5 4 . 8}\end{array}$ & $\begin{array}{l}14.0 \\
48.5\end{array}$ \\
\hline 09 & Mecânica tanque 3 & $\begin{array}{l}1 \\
2\end{array}$ & $\begin{array}{r}47,5 \\
3,9\end{array}$ & $\begin{array}{l}63,5 \\
14,7\end{array}$ & $\begin{array}{r}55,5 \\
8.5\end{array}$ \\
\hline 09 & Mecânica tanque 4 & $\begin{array}{l}1 \\
2\end{array}$ & $\begin{array}{l}28,0 \\
39,4\end{array}$ & $\begin{array}{l}30,0 \\
46,0\end{array}$ & $\begin{array}{l}29.0 \\
42,5\end{array}$ \\
\hline 10 & Mecânica tanque 1 & $\begin{array}{l}1 \\
3\end{array}$ & $\begin{array}{l}74,7 \\
50,9\end{array}$ & $\begin{array}{r}185.4 \\
61,1\end{array}$ & $\begin{array}{r}119,5 \\
\mathbf{5 4 , 5}\end{array}$ \\
\hline 10 & Mecânica tanque 2 & $\begin{array}{l}1 \\
3\end{array}$ & $\begin{array}{l}28,0 \\
25,5\end{array}$ & $\begin{array}{l}44.5 \\
33.4\end{array}$ & $\begin{array}{l}36.0 \\
29.5\end{array}$ \\
\hline
\end{tabular}

tas empresas 7 trabalham pelo processo de desengraxamento a quente, utilizando para isto um total de 13 tanques, dos quais 7 ocupados para fins de galvanoplastia e 6 para fabricação de máquinas. Quatro empresas utilizam o proceso de desengraxamento a frio e uma delas utiliza os dois processos.

Para efeito de avaliação ambiental de vapores de tricloroetileno foram definidos os seguintes pontos em instalações de desengraxamento a quente:

Ponto 1 - acima do tanque, na zona respiratória do operário;
Ponto 2 - na zona respiratoria do operário, junto ao local onde as peças limpas são amontoadas aguardando a continuidade do processo.

Ponto 3 - ponto representativo do ambiente, geralmente no processamento do material desengraxado e seco.

Os pontos de amostragem nas instalações de desengraxamento a frio estão descritos juntamente com os resultados na Tabela 2.

\subsection{Captaçăo e análise de vapores de iricloroetileno}

Para a determinaçãu do TRI no ar seguiu-se ". método de Fahy como é descrito 
STETTINER, H. M. A. et al. Risco de intoxicação profissional por tricloroetileno em processos de desengraxamento no municipio de $\mathrm{S}$ Paulo, Brasil. Rev. Saúde pübl., S. Paulo. $11: 395-404,1977$.

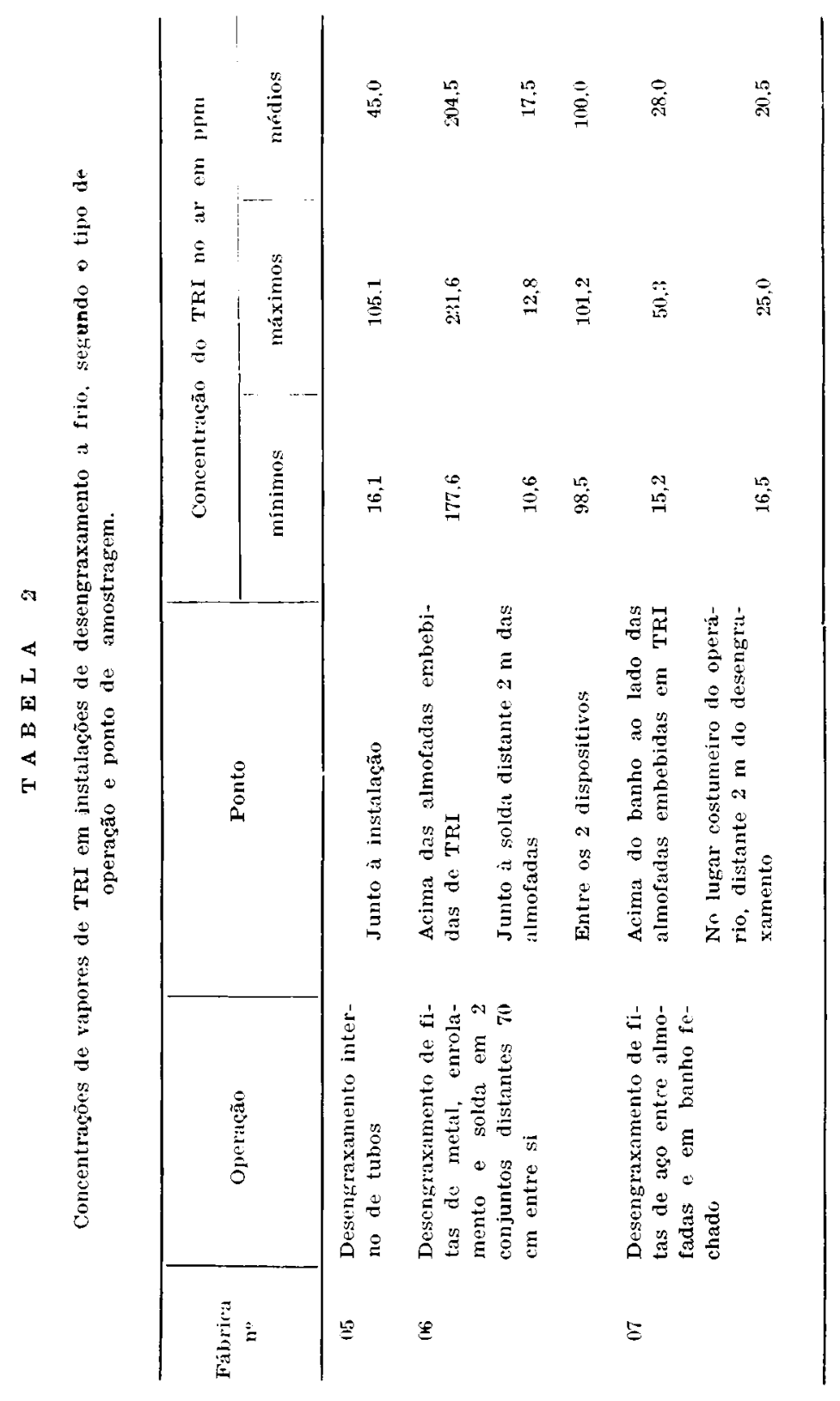


STETTINER, H. M. A. et al. Risco de in toxicação profissional por tricloroetileno em processos de desengraxamento no município de $\mathbf{S}$. Paulo, Brasil. Rev. Saúde públ., S. Paulo, $11: 395-404,1977$.

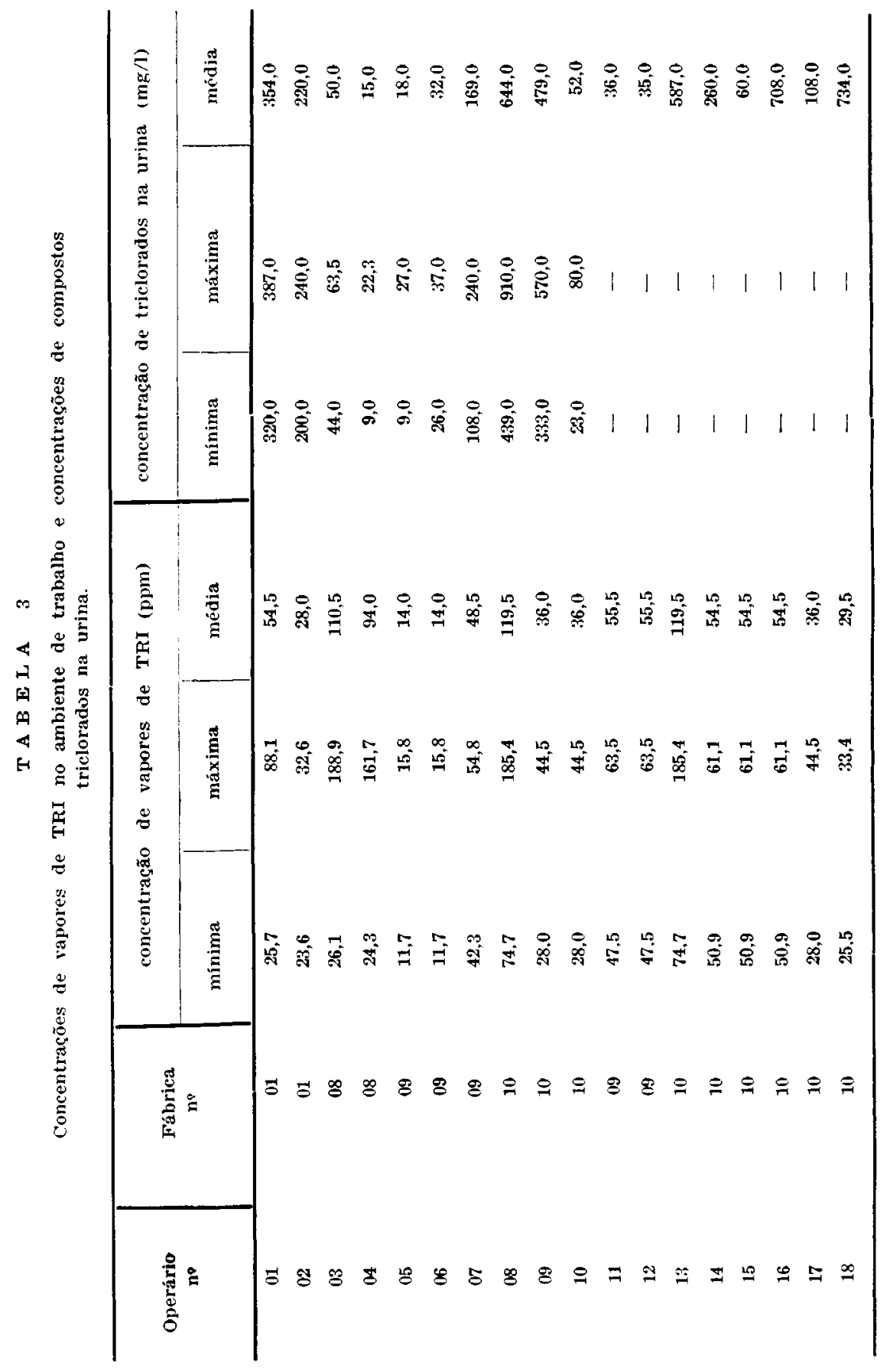


STETTINER, H. M. A. et al. Risco de intoxicação profissional por tricloroetileno em processos de desengraxamento no município de $\mathrm{S}$. Pauln. Brasil, Rev. Saude pübl., S. Paulo, $11: 395-404,1977$

poï Elkins ${ }^{1}$. Os vapores são captados por aasorçau em smicagel cuntlua em tubos de vidro em torma de " $U$ ' A eluıçao e teita com alcool isupropilico e uma alicota aesta soluçáo é hidrolıada com hidroxıdo de potássio. U cloreto de potássio resultante é utulado com nitrato de prata $0,111 \mathrm{~N}$ pelo metodo clássico de MUHR.

\subsection{Determinaçâo de meiabólitos na urina}

Os dois metabólitos triclorados do TRI, o ácido tricloroacético ( $\mathrm{CCl}_{3}$. $\left.\mathrm{COOH}, T \mathrm{TA}\right)$ e o tricloroetanol $\left(\mathrm{CCl}_{3} \mathrm{CH}_{2} \mathrm{OH}\right.$, TCE) aparecem na urina ligados ao ácido glicurônico '. Sua determinação na urina permite avaliar a exposição a vapores de TRI. A excreção destes dois clorocompostos obedece a ritmos bastante diferentes: o $\mathrm{TCE}$ aparece logo depois da exposição enquanto que o TCA tem a eliminação máxima depois de alguns dias '. Nesta pesquisa nâo foi viável controlar eficientemente o tempo de emissão das urinas em relação aos dias e às horas de trabalho com o TRI. Assim, limitou-se a determinar " conjunto das substâncias tricloradas.

Seguiu-se o método colorimétrico de Seto e Schultze ${ }^{11}$, que se baseia na reação de Fujiwara. O TCA reage com piridina $e$ hidróxido de potássio, resultando uma coloração vermelha que obedece à lei de BeerLambert. Para medir a soma total de substâncias tricloradas, o TCE presente é oxidado para TCA no início do procedimento analítico e a soma dos triclorados é calculada em $\mathrm{mg}$ de TCA por litro de urina.

\section{R E S U L T A D O S}

Os resultados obtidos encontram-se distribuidos nas Tabelas 1,2 e 3 .

\section{DISCUSS $\mathrm{A}$}

Pelos resultados das Tabelas 1 e 2 verifica-se que grande parte das concentraçóes médias dos locais de trabalho estão abaixo de $100 \mathrm{ppm}$, que é tido como o limite de tolerância mais aceito, o que nos levaria a concluir pela baixa periculosidade desses ambientes de trabalho. Ressalva-se, porém, que os dados, referem-se a resultados de uma amostragem e não refletem necessariamente a exata concentração de vapores de TRI a yue o operário está exposto durante toda a jornada de trabalho, visto que estas concentrações não são uniformes em todo 0 local de trabalho, variando segundo a aproximação da fonte de contaminação, condições de ventilação do local, temperatura, volume de TRI empregado, etc.

Por outro lado, a exposiçáo dos trabalhadores também não é uniforme, variando segundo sua permanência malor ou menor em determinado ponto, sua atividade, ou ainda seu comportamento, utilizando ou não os dispositivos de proteção ou até inalando intencionalmente os vapores do solvente Assim, os resultados da avaliação da excreção urinária de compostos triclorados não será necessariamente maior nos trabalhadores de locais com maior concentração média de vapores de TRI, podendo-se $p^{(1)-}$ rém observar que embora de um modo geral não exista correlação entre o aumento de TCA urinário e 0 aumento de concentração de TRI, em alguns casos notou-se esta tendência, coincidindo com as observações de lkeda e col. ${ }^{\prime}$

Ressalta-se o caso do operário n! 18 que apresentou $734 \mathrm{mg}$ de $\mathrm{TCA} / 1$ na urina e em cujo local de trabalho foi detectado apenas 29,5 ppm de TRI, indicando que as condições reais de trabalho não são aquelas reveladas quando das amostragens do local de trabalho, ou que o operário está absorvendo uma quantidade "extra" de TRI por via cutânea, ou respiratória, devido à grande falta de cuidados nas operaçōes, ou mesmo intencionalmente.

Caso inverso é o do operário $n^{\circ} 4$ que exposto num local de trabalho que apresentou até 161,7 ppm (média $94 \mathrm{ppm}$ ) de vapores de TRI revelou apenas $15 \mathrm{mg}$ de TCA/1 de urina. Outra observação interessante é que trabalhadores expostos ao 
STETTINER, H. M. A. et al, Risco de intoxicação profissional por tricloroetileno em processos de desengraxamento no município de $\mathrm{S}$. Paulo, Brasil. Rev. Saúde públ., S. Paulo, $11: 395-404,1977$.

mesmo ambiente e trabalhando lado a lado apresentaram grande variação no teor de TCA urinário.

Se por un lado não foranı encontradas grandes concentrações de vapor de TRI nos locais de trabalho, o que nos levaria a concluir pela baixa periculosidade destes, há que se observar que dos 18 trabalhadores examinados 9 apresentaram concentraçóes de TCA urinário em torno de $300 \mathrm{mg} / 1$, que é o limite de tolerância biológica segundo Elkins ' , indicando que as medidas de controle ambiental são necessárias porém não suficientes para uma perfeita proteção contra a intoxicação profissional, pois o comportamento do trabalhador deve ser observado e modificado no sentido de uma correta utilização das medidas de se- gurança, evitando-se exposiçnes desnecessárias ao solvente.

$$
\text { 8. CON CIUS OE }
$$

Em 22\% dos locais de trabalho avaliados, foram encontradas concentrações médias de vapores de TRI acima de $100 \mathrm{ppm}$ (limite de tolerância).

Cincoenta por cento dos expostos a vapores de TRI apresentaram concentrações de TCA na urina em torno de $300 \mathrm{mg} / 1$, comprovando a existência de risco ocupacional.

Não foi encontrada correlação entre aumento das concentraçōes médias ambientais de vapores de TRI e concentrações de TCA na urina de pessoal exposto.

RSPU-B/371

STETTINER, H. M. A. et al. /Risk of occupational intoxication due to trichloroethylene in grease removal operations in the county of S. Pallo, Brazil.] Rev. Saúde públ., S. Paulo, 11:395-404, 1977.

ABSTRACT: The toxic effects of trichloroethylene (TRI) vapors are explained. The TRI vapors have been determined in the air of workingplaces where the liquid is used to remove oil and grease from metal surfaces. Its metabolites, tricehorocetic acid and trichloroethanol have been determined in the urine of exposed persons. The TRI vapors concentrations and urinary TCA resuts confirm the potential danger represented by the use of trichloroethylene in degreasing processes.

UNITERMS: Trichloroethylene poisoning. Industrial medicine. Occupational diseases.

\section{REFERENCIAS BIBLIOGRAFICAS}

1. ELKINS, H. B. The chemistry of industrial toxicology. 2nd ed. New York. John Wiley, 1959

2. GOELZER, B. I. F. Prevenção de riscos de utilização de desengraxantes. $B$ ol. inf. Fundacentro, $1(8 / 10): 2$, ago./ out., 1970.

3. HUNTER, D. The diseases of occupations, 4th ed. London. The English Universities Press, 1971.

4. IKEDA, H. et al, Urinary excretion of total trichloro compounds, trichloroe- thane and trichloroacetic acid as a measure of exposure to tri and tetrachloroethylene. Brit. $J$. industr. Med,, 29: 328-33. Jul. 1972.

5. LLOYD, W. J. et al. Background information on trichloroethylene. $J$, occup. Med, 17: 60:3-5, 1975.

6. NATIONAL INSTITUTE FOR OCCUPATIONAL SAFETY AND HEALTH. Occupational exposure to trichloroethylene. Washington, D.C., Department of Health. Education and Welfare. 1973. 
STETTINER, H. M. A. et al. Risco de in toxicação profissional por tricloroetileno em processos de desengraxamento no municipio de $\mathbf{S}$. Paulo, Brasil. Rev. Saúde pübl., S. Paulo, $11: 395-404,1977$,

7. OGATA, M. et al. Excretion of organic chlorocompounds in the urine of persons exposed to vapors of tri and tetrachloroethylene. Brit. J. industr. Med., 28: 386-91, 1971.

8. PLUNKETT, E. R. Manual de toxicologia industrial. Bilbao, Ediciones Urmo, 1968.

9. SAAD, E. G. Acidentes, segurança, higiene e medicina do trabalho. São Pau10. Fundacentro, 1972.

10. SECCHI, G. C. et al. Composizione chimica attuale delle trieline commerciali e loro effetti epatotossici, studio clinico ed enzimologico. Med. d. Lavoro, 59: 486-97, 1968

11. SETO, T. \& SCHULTZE, M, O. Determination of trichloroethylene. trichlo- roacetic acid and trichloroethanol in urine. Analyt. Chem., 28:1925-9, 1956.

12. SIMONIN, C. Medicina del trabajo. Madrid, Ediciones Morata, 1959.

13. STEWART, R. D. et al, Degreasers flush: dermal response to trichloroethylene and ethanol. Arch. environm. Hith, 29:1-5, 1974 .

14. WEICHARDT, H. \& BARDODEJ, $Z$. Die Bestimmung von Trichoressigsaeure und Trichloraethanol im Urin ron Trichloraethylenarbeitern. Z Zbl. Arbeitsmed., 20: 219-21, 1970 .

Recebido para publicação em 09/03/197\% Aprovado para publicação em 28/03/197\% 